\title{
LA NORMATIVA DE LA COFRADÍA \\ DE LA DOCTRINA CRISTIANA (1683)
}

\section{REGULATIONS OF THE CONFRATERNITY \\ OF CHRISTIAN DOCTRINE (1683)}

\author{
Rocío Silva Herrera \\ Universidad Pontificia de México \\ Instituto Superior de Ciencias Religiosas \\ shipros@gmail.com \\ ORCID: 0000-0002-7964-0240
}

\section{Resumen}

Este documento contiene el modelo pastoral tridentino, urbano e incluyente, fomentado por los sacerdotes de la Unión de San Felipe Neri, a través de la Cofradía de la Doctrina Cristiana, cuyos miembros se comprometían a ser instructores en la fe católica de acuerdo con su status eclesial: laico, clérigo o religioso. Dado que la unión fue una fraternidad sacerdotal, la cofradía no estuvo ligada a una parroquia o doctrina, sino que sus actividades fueron una extensión del ministerio diocesano en diversos espacios de la ciudad de México, bajo la inspiración del magisterio del episcopado novohispano y del espíritu filipense. El contenido de las Reglas de 1683 contribuyó al proyecto del arzobispo Francisco de Aguiar y Seijas de fortalecer y ordenar las cofradías de su jurisdicción.

Palabras clave: Cofradía Doctrina Cristiana; Unión de San Felipe Neri; cofradías novohispanas; clérigos siglo XVII; Francisco de Aguiar y Seijas.

\begin{abstract}
This document contains the Tridentine, urban, and inclusive pastoral model promoted by priests of the Congregation of Saint Philip Neri, through the Confraternity of Christian Doctrine, whose members promised to be instructors of the Catholic faith according to their ecclesial status: lay, cleric or religious. Since the Congregation was a priestly fraternity, the Confraternity was not linked to a parish or doctrine; its activities were an extension of diocesan ministry in various areas of Mexico City, under the inspiration of the episcopate of New Spain and in the spirit of the Congregation of St. Philip Neri. The content of the rules of 1683 contributed to the project of Archbishop Francisco de Aguiar y Seijas to strengthen and order the confraternities within his jurisdiction.
\end{abstract}

Keywords: Confraternity of Christian Doctrine; Congregation of San Felipe Neri; New Hispanic brotherhoods; 17th century clergymen; Francisco de Aguiar y Seijas.

\section{Información del artículo}

Recibido: 29 de abril de 2020.

Aceptado: 5 de junio de 2020 .

DOI: http://dx.doi.org/10.22201/iih.24486922e.2020.63.75701 


\section{Introducción}

El documento que se presenta contiene las reglas y constituciones de la Cofradía de la Doctrina Cristiana elaboradas en 1683; se trata de la revisión de las primeras reglas que no fueron aprobadas "por varios accidentes". ${ }^{1}$ La cofradía fue fundada en la Ciudad de México en 1678 por los sacerdotes de la Unión de San Felipe Neri, la cual se estableció en 1658 por un grupo de clérigos criollos. ${ }^{2}$

En 1677 la unión se agregó a la Archicofradía de la Doctrina Cristiana de Roma, ${ }^{3}$ hecho que permitió la fundación de la Cofradía de la Doctrina Cristiana en México para promover, a través de la enseñanza de la fe, la reforma de las costumbres, la salvación de las almas y el fervor de los sacerdotes con el fin de sostener el edificio espiritual, así como para beneficiarse de las indulgencias compartidas de su homónima romana. ${ }^{4}$

Luis Ávila abordó el tema de esta cofradía para señalar que su fundación fue la respuesta de la unión a la preponderancia dada por el Tercer Concilio Provincial Mexicano a la enseñanza de la doctrina católica. Según el autor, este cometido estuvo vigente hasta por lo menos 1731, año en el que un padre filipense aseveró que la cofradía había mantenido su fin de mudar "del miserable estado de la culpa, á el felicissimo de la gracia". ${ }^{5}$ También dio noticia del catecismo que imprimió la cofradía en su edición de 1679, del Sumario de las indulgencias de 1712, así como de las Reglas y sumario de $1731 .^{6}$

La reglamentación de 1683 ofrece elementos para nombrar a la Cofradía de la Doctrina Cristiana con los conceptos historiográficos "mixta" y "no retributiva”, y también brinda otros aspectos, que pueden ser conceptualizados

${ }^{1}$ Reglas y Constituciones, que han de observar los Congregantes de la Unión y Confraternidad de Nuestro Padre San Felipe Neri, fundada en su Oratorio en esta Ciudad de México, y sus Ministros Operarios, por lo que toca al Instituto de la enseñanza de la Doctrina Cristiana, México, 12 de febrero de 1683, Archivo General de la Nación de México (en adelante AGN), Bienes Nacionales, v. 944, exp. 2, f. 3v.

${ }^{2}$ Luis Marín Cano Arenas, "La Congregación del Oratorio de México: origen e identidad", Annales Oratorii, n. 12 (2014): 109-113.

${ }^{3}$ La Archicofradía de la Doctrina Cristiana de Roma fue fundada por el papa Paulo V a principios del siglo XVII para instruir en la religión a la juventud de Roma; $c f r$. Ludovico Pastor, Storia dei papi, v. XII (Roma: Desclée-Editori Pontifici, 1943), 203.

${ }^{4}$ AGN, Bienes Nacionales, v. 944, exp. 2, f. 2v-3r.

${ }^{5}$ Luis Ávila Blancas, Bio-bibliografía de la Congregación del Oratorio de San Felipe Neri de la ciudad de México, siglos XVII-XXI (Querétaro: Imprenta Hidalgo, 2008), 339.

${ }^{6}$ Ávila Blancas, Bio-Bibliografía de la Congregación del Oratorio, 315, 317. 
desde una perspectiva interdisciplinar, tales como la inclusión de diversos estamentos eclesiásticos, un gobierno dependiente del clero agrupado en una fraternidad sacerdotal, y operar a manera de prolongación del ministerio pastoral diocesano más allá de los límites administrativos de una parroquia.

Los miembros de la cofradía eran los clérigos de la unión; otros presbíteros, a quienes se les dio el nombre de ministros operarios, provenientes del clero regular y diocesano, especialmente los canónigos y los curas del Sagrario; y laicos de "qualesquier personas de ambos sexos, de qualquier edad, estado, calidad y condicion". ${ }^{7}$

La historiografía ha llamado cofradías mixtas a las que admitían gente proveniente de diversas castas. La Cofradía de la Doctrina Cristiana, además de recibir cualquier tipo de personas seglares, también acogió distintos grupos eclesiales: clérigos, religiosos y laicos; por lo que se le puede llamar incluyente desde el punto de vista eclesiológico. Del mismo modo, es de resaltar su nexo con el cabildo y los curas del Sagrario cuando el afianzamiento de las instituciones eclesiásticas, iniciado desde fines del siglo XVI, ${ }^{8}$ estaba en una fase muy avanzada hacia $1683 .{ }^{9}$

La inclusión eclesial fomentada por la cofradía respecto de sus miembros no aplicó en su gobierno, ya que éste recayó exclusivamente en el prefecto y oficiales de la unión, quienes nombrarían, de entre los sacerdotes de la misma, un procurador de los bienes materiales y espirituales, un encargado de llevar el Libro de asientos, y algunos visitadores que supervisaran la asistencia a la enseñanza y progreso de los cofrades, junto con la atención ofrecida por los ministros operarios, quienes eran los encargados de dar la doctrina.

Las reglas de 1683 no piden llevar Libro de cuentas, sólo aluden a que, al momento de la adscripción, se pedía un real para cubrir el costo del Sumario de las indulgencias y el Catecismo. ${ }^{10}$ La historiografía ha nombrado no retributivas a este tipo de cofradías. Evitar involucrarse en cuestiones de beneficencia pública o inversión de capitales reforzó la operatividad del

${ }^{7}$ AGN, Bienes Nacionales, v. 944, exp. 2, f. 4r.

${ }^{8}$ Antonio Cano Castillo, El clero secular en la diócesis de México (1519-1650). Estudio histórico-prosopográfico a la luz de la legislación regia y tridentina (Zamora, Michoacán, México: El Colegio de Michoacán; México: Universidad Pontificia de México, 2017), 701-702.

${ }^{9}$ Leticia Pérez Puente, Tiempos de crisis, tiempos de consolidación (México: Universidad Nacional Autónoma de México, Centro de Estudios sobre la Universidad; Zamora, Michoacán, México: El Colegio de Michoacán; México: Plaza y Valdés Editores, 2005), 15, 200-203.

${ }^{10}$ AGN, Bienes Nacionales, v. 944, exp. 2, f. 5v. 
adoctrinamiento de la cofradía. Además, es indicio de la holgura económica de la unión, conformada por ese entonces por algunos sacerdotes de la élite clerical. ${ }^{11}$ ¿Se puede plantear que la cofradía era en sí una obra de caridad intelectual, entendida ésta como una diaconía a la verdad para enderezar conceptos y conductas? ${ }^{12}$

La enseñanza se daba en la sede de la unión ${ }^{13}$ y en otros seis sitios, llamados escuelas: en la catedral, las parroquias de santa Catalina, mártir y de la Santa Veracruz, la iglesia de la Santísima Trinidad, el Hospital de Jesús Nazareno, y en los portales de la plaza mayor donde parecía "mas precisa y necessaria la enseñança de la Doctrina Christiana por la mucha gente vulgar que ay en ella, y la mas necessitada de este socorro espiritual". ${ }^{14}$

Esta variedad de escenarios estableció vínculos con auditorios estables en las parroquias y con otros fugaces en la plaza al aire libre a manera de misión popular. ${ }^{15}$ La actividad de la cofradía no estuvo vinculada a una

11 Ávila Blancas, Bio-bibliografía de la Congregación del Oratorio, 5.

12 Para acercarse al actual concepto de caridad intelectual: Jesús Villagrasa Lasaga, "La caridad intelectual de Joseph Ratzinger. Los dos primeros años de magisterio de Benedicto XVI (19 de abril de 2005-7 de julio de 2007)”, Ecclesia: Revista de cultura católica, 4 (2007): 499-510.

${ }^{13}$ El claustro del Oratorio, para acoger a sacerdotes enfermos o a los que quisieran residir allí, comenzó a construirse en 1684 a solicitud del arzobispo Francisco de Aguiar y Seijas. En 1687 se inició la ampliación de la capilla, la cual se concluyó por un donativo de 4200 pesos del deán y miembro de la unión, Diego Ortiz de Malpartida Centeno. Actualmente, en este edificio se alberga la Biblioteca "Miguel Lerdo de Tejada”, en la calle República del Salvador en el Centro Histórico de la Ciudad de México; cfr. Antonio de Robles, Diario de sucesos notables, 1665-1703, t. II, ed. y pról. de Antonio de Castro Leal (México: Porrúa, 1946), 111-112; Julián Gutiérrez, Memorias históricas de la Congregación de el Oratorio de la ciudad de México, y fundada con auctoridad ordinaria, después, con la apostólica, erigida y confirmada en Congregación de el Oratorio, copiada a el exemplar de la que en Roma fundó el esclarecido patriarca san Phelipe Neri, en las quales se da noticia, asi de su fundación como de su apostólica erección y confirmación, y juntamente de muchas de las personas, que en uno y otro tiempo la han ilustrado/recogidas y publicadas por el Julián Gutiérrez Dávila, presbytero, preposito, que fue, de dicha Congregación del Oratorio de México (México: Doña María de Ribera, 1736), parte I, lib. I, cap. II; Ávila Blancas, Bio-bibliografía de la Congregación del Oratorio, 4; Martha Fernández, "Rastros y efectos. El Museo del Escritor en el ex claustro del Oratorio de San Felipe Neri ‘el Viejo’”, Imágenes. Revista electrónica del Instituto de Investigaciones Estéticas, http://www.esteticas.unam.mx/revista_imagenes/rastros/ras_fernandez12.html, consultado el 9 de junio de 2020.

${ }^{14}$ AGN, Bienes Nacionales, v. 944, exp. 2, f. 6r. El padre José de Lezamis, confesor del arzobispo Francisco de Aguiar y cofrade de la unión, solía predicar en la escuela de los portales; cfr. Gutiérrez, Memorias históricas de la Congregación de el Oratorio, parte I, lib. I, cap. viII, n. 623 .

${ }^{15}$ La predicación en la vía pública fue una de las formas adoptadas por las misiones tridentinas para lograr la reforma de las costumbres, la cohesión conductual y doctrinal de 
parroquia o doctrina en virtud de que la unión era una hermandad clerical, pero sí representó una extensión del servicio pastoral diocesano en diversos sitios de la urbe. Es importante recalcar que los padres de la unión no eran clérigos regulares, obligados a vida comunitaria, sino sacerdotes diocesanos formados y viviendo como tales. ${ }^{16}$

A la enseñanza en las escuelas, se añadía la obligación de los cofrades laicos de promover la formación en la fe en sí mismos y en sus respectivas familias. El ideal conjunto de la enseñanza de la doctrina fue puesto bajo el patronazgo de la Exaltación de la Santa Cruz. El 3 de mayo, la cofradía tenía misa y sermón en la sede de la unión, luego salían en solemne procesión a las cuatro de la tarde hacia la catedral en donde se concluía con una plática sobre la doctrina cristiana. En las Reglas prevalece la idea de que este tipo de manifestaciones públicas de fe eran ejemplo de piedad. ${ }^{17}$

La intención pastoral incluyente de la cofradía en el aspecto social, al acoger a laicos "de qualquier edad, estado, calidad y condicion", respondió al rostro multiétnico de la población de la ciudad de México, cuya demografía española, india y de otras castas, aumentó más del 50 por ciento en las últimas décadas del siglo XVII, resultando de ello una notable complejidad étnica. ${ }^{18}$

Las Reglas de 1683 se elaboraron durante el gobierno del arzobispo Francisco de Aguiar y Seijas, quien desplegó una estrategia de regulación y fortalecimiento de las cofradías en su jurisdicción como parte de su interés general por la reforma espiritual de los fieles, la aplicación de la normativa tridentina y del III Concilio Provincial Mexicano, para lo cual nombró jueces eclesiásticos a los que quedaron sujetas. ${ }^{19}$

la sociedad católica hispánica; $c f r$. Miguel Ángel Núñez Beltrán, La oratoria sagrada de la época del barroco. Doctrina, cultura, actitud ante la vida desde los sermones sevillanos del siglo XVII (Sevilla: Universidad de Sevilla, 2000), 433.

${ }^{16}$ La erección canónica de la Unión como Congregación del Oratorio se hizo en 1697 por la bula Ex quo divina Majestas de Inocencio XII. Luego de haber obtenido el pase real en 1701, se realizó la celebración pública el 12 de febrero de 1702. A partir de esta fecha, la vida comunitaria fue obligatoria; cfr. Marín Cano Arenas, "La Congregación del Oratorio de México: origen e identidad", 109-113.

${ }^{17}$ AGN, Bienes Nacionales, v. 944, exp. 2, f. 5r.

18 Óscar Mazín, "Espacio social y jurisdicción en los Padrones del Sagrario Metropolitano de México", en Los "Padrones" de confesión y comunión de la parroquia del Sagrario Metropolitano de la ciudad de México, de Óscar Mazín y Esteban Sánchez de Tagle (México: El Colegio de México; Murcia, España: Red Luminaria, 2009), 54-55.

${ }^{19}$ Rodolfo Aguirre Salvador, Cofradías y asociaciones de fieles en la mira de la Iglesia y de la Corona: arzobispado de México, 1680-1750 (México: Universidad Nacional Autónoma de México, 2019), 17, 22, 71-124. 
Una vez que Aguiar aprobó la reglamentación de la Cofradía de la Doctrina Cristiana, en abril de 1683, a través de un edicto, mandó que una de las cofradías erigidas canónicamente en cada iglesia cabecera de partido de todo su arzobispado, que no contara con indulgencias propias, se agregara a la Archicofradía de la Doctrina Cristiana de Roma; o en caso de que no existiera cofradía alguna aprobada por el ordinario, concedió facultad a los ministros para que fundaran una. ${ }^{20}$

La reglamentación de 1683, de la que fueron tomados algunos textos a la letra para el edicto de Aguiar, ofreció un cauce al prelado para crear un vínculo entre los fieles y él mismo como cabeza de la iglesia diocesana y patrón de las cofradías de la doctrina cristiana. ${ }^{21}$ Con ello, además de dotar a los fieles con profusas gracias espirituales, se amplió la presencia de la mitra, ya que este lazo de gobierno, se robusteció durante sus visitas pastorales $^{22}$ por estar el prelado en persona entre los feligreses, supervisar el

20 "Edicto del arzobispo de México Dr. Dn. Francisco de Aguilar y Seixas, para que las iglesias parroquiales de cada beneficio o doctrina del arzobispado, se agreguen a alguna Cofradía a la Archi-cofradía de la Doctrina Cristiana fundada en la iglesia de San Pedro de Roma”, México 8 de abril de 1683, en Colección de documentos eclesiásticos de México, o sea antigua y moderna legislación de la Iglesia mexicana, comp. de Fortino H. Vera, t. I (Amecameca: Imprenta del Colegio Católico, 1887), 454-459, http://cdigital.dgb.uanl.mx/la/ 1080015731_C/1080015731_T1/1080015731_042.pdf, consultado el 4 de junio de 2020.

${ }^{21}$ El edicto de Francisco de Aguiar fue acogido progresivamente, pues durante su primera visita pastoral, iniciada a fines de 1683 a la zona de la Huasteca, había dos; en tanto que en su cuarta visita (1686-1687) por la zona de las Amilpas se registraron siete (Chalco, Totolapa, Tlayacapan, Cuautla, Temamatla, Milpa Alta y Atlapulco). Rodolfo Aguirre afirma que hacia 1690 había 15 cofradías; cfr. Rodolfo Aguirre, "La reorganización de cofradías del arzobispado de México por Aguiar y Seixas", en Expresiones y estrategias. La Iglesia en el orden social novohispano, coord. de María del Pilar Martínez López-Cano y Francisco Javier Cervantes Bello (México: Universidad Nacional Autónoma de México, Instituto de Investigaciones Históricas, 2017), 275, http://www.historicas.unam.mx/publicaciones/publicadigital/ libros/expresiones/04_09_reorganizacion.pdf, consultado el 4 de junio de 2020; Rocío Silva Herrera, "El perfil pastoral de Francisco de Aguiar y Seijas. Análisis desde su visita pastoral a partir del Libro de visita (4 de diciembre de 1686-9 de abril de 1687)" (tesis de maestría, Universidad Pontificia de México, 2010), 174-178. La promoción de las cofradías de la doctrina cristiana por el arzobispo Aguiar ha sido señalada en Aguirre Salvador, Cofradías y asociaciones de fieles, 101.

${ }^{22}$ Francisco de Aguiar y Seijas visitó el arzobispado de México en cinco cordilleras entre 1683 y 1688. En la última tenía previsto llegar hasta el Puerto de Acapulco, pero no lo logró a causa de su precario estado de salud; cfr. Rocío Silva Herrera, "Francisco de Aguiar y Seijas, pastor del rebaño”, Cuadernos de Estudios Gallegos, n. 127 (2014), 123-124, http:// estudiosgallegos.revistas.csic.es/index.php/estudiosgallegos/article/view/369, consultado el 18 de junio de 2020 . 
funcionamiento de las cofradías, y dejar jueces eclesiásticos para inspeccionarlas.

El patrocinio de Aguiar sobre las cofradías de la doctrina cristina también está ligado a su afinidad personal con la espiritualidad filipense, pues durante la primera cordillera de su visita pastoral en Michoacán, fundó en la ciudad de San Luis Potosí, la Cofradía y Hermandad y Unión de San Felipe Neri con los clérigos del lugar; además, él mismo formó parte de la unión de la ciudad de México. ${ }^{23}$

El documento que se presenta reposa en el Archivo General de la Nación de México en el grupo documental Bienes Nacionales, volumen 944, dentro del expediente 2. El manuscrito está compuesto por 14 fojas, presenta las firmas de las autoridades de la unión y está fechado el 12 de febrero de 1683. En general, en la transcripción se conservó la ortografía original y se desataron las abreviaturas, señalando con cursivas las letras omitidas. Todas las indicaciones de la transcriptora se anotaron entre corchetes.

El escrito contiene una introducción y tres capítulos. En la introducción se justifica el fin de la cofradía y se hace un recuento histórico de su conformación. El primer capítulo trata el asunto del gobierno de la cofradía, sus fiestas patronales e indulgencias. El segundo capítulo expone las normas que debían observar los ministros operarios y visitadores en la atención de las escuelas. El tercer capítulo aborda la obligación de los cofrades laicos como promotores de la formación en la fe de sus hijos y demás personas de su casa.

Las fuentes que dan sustento a la normatividad de la cofradía muestran una notable influencia magisterial del Tercer Concilio Provincial Mexicano, de los concilios de Milán y del Concilio de Trento. Existen citas de diversos documentos eclesiásticos contenidos en el Bulario de Angelo Cherubini. También hay presencia de la obra de Agustín Barbosa Pastoralis solicitudinis: sive, de officio et potestate parochi tripartita descriptio. Con una sola mención están el evangelio de Mateo, la bula de canonización de san Felipe Neri de Urbano VIII, la Vida de san Francisco Javier del padre João Lucena y la Carta de Clemente Romano a Santiago. Estas fuentes responden al perfil clerical de los miembros de la unión y a su inspiración en el espíritu filipense.

${ }^{23}$ Archivo Histórico Casa Morelos, Diocesano, Gobierno, Visitas, Asientos, c. 57, exp. 14, f. 75v, 91r; Gutiérrez, Memorias históricas de la Congregación de el Oratorio, parte I, lib. I, cap. 8. 


\section{DOCUMENTO}

[F. 1r-1v, en blanco.]

[F. 2r] Reglas y Constituciones que han de observar los Congregantes de la Vnion y Confraternidad de Nuestro Padre San Phelipe Neri, fundada en su Oratorio en esta Ciudad de Mexico, y sus Ministros Operarios, por lo que toca al Instituto de la enseñança de la Doctrina Christiana.

\section{[Al margen] Concilio Mexicano libro $1^{\circ}$ titulo $1^{\circ}$ de Fidei professione $\S 1^{\circ}$}

El fundamento del edificio espiritual, la raiz de nuestra justificacion, y de la Bienaventurança que esperamos, es la Fe, sin la qual es impossible agradar a Dios. Y assi lo primero en que el Christiano debe instruirse, es en lo que debe creer, en los Mandamientos de Dios, y de la Iglesia, que debe guardar, en lo que ha de pedir y suplicar a la Magestad divina, y en los instrumentos de que se ha de valer para adquirir y conservar la gracia, y aumentar las virtudes. Y el medio para conseguir este fin, es la enseñança de la Doctrina Christiana y rudimentos de nuestra Religion Catholica y su explicacion, que como tan necessaria à todo genero de personas, y en particular à los pequeñuelos, gente ruda y menos entendida, està tan encargada y mandada, como es notorio, por el Sagrado Concilio Tridentino à los Ministros evangelicos, y recomendada por los Sumos Pontifices en diversas Bulas Apostolicas y en especial por vna del

[Al margen] tomo $2^{\circ}$ del Bulario de Querubini Constitución 137. Et Barbosa de Officio Parochi parte $1^{\mathrm{a}}$ capítulo 15 . número $8^{\circ}$. Concilio Millanese $2^{\circ}$ decreto $2^{\circ}$

Santo Pio Quinto, que empieça, Ex debito, su data en Roma a seis de Octubre del año de mil quinientos y setenta y uno: en que manda Su Santidad a todos los Ordinarios, que erijan y funden en sus Diocesis Cofradias ò Congregaciones para enseñar à los niños, y demas personas que lo huvieren menester, la Doctrina Christiana, è instruirlos en las buenas costumbres de que se necessita para conse-

[Al margen] tomo 3 Bullarium Cherubini Constitución 35. Ex credito et refert Barbosa de Officio Parochi vbi supra n. 9.

guir la vida eterna. Y otra de Nuestro Muy Santo Padre Paulo Quinto de felice recordacion, su data en Tusculi à seis de Octubre del año de mil seiscientos y siete: en que Su Santidad movido del zelo Pastoral y deseo de la 
mayor hon[f. 2v]ra de Dios y bien de las almas, Motu proprio erigio vna Archicofradia en la celeberrima Basilica del Principe de los Apostoles y Nuestro Padre San Pedro cuyo principal instituto fuesse la enseñança y explicacion de la Doctrina Christiana à los niños, y demas gente necessitada de aprenderla; enriqueciendola de muchas indulgencias, gracias y privilegios: y vno de ellos el poder agregar en qualquier parte del Orbe Otras qualesquiera Cofradias ò Congregaciones del mismo instituto fundadas $\mathrm{y}$ erigidas, ò que en adelante se erigiessen y fundassen canonicamente con authoridad de los Ordinarios de los lugares; y que à las dichas Cofradias ò Congregaciones que erigidas les pudiessen comunicar todas las gracias, indulgencias y privilegios contenidos en la Bula referida para que atraidos los Ministros Operarios, y los demas Fieles de Christo, con el incentivo y ganancia del Celestial tesoro de tantas indulgencias, se dedicassen con todo fervor y ardiente charidad al exercizio de Ministerio tan Santo, y de tanta importancia para aumentar el edificio espiritual de la iglesia. Y aviendose fundado canonicamente con authoridad ordinaria en esta Ciudad de Mexico Nuestra Vnion y Confraternidad de Clerigos Presbyteros del Oratorio de Nuestro Padre San Phelipe Neri para ayudar à los próximos con la Predicacion Evangelica y enseñança de la Doctrina Christiana (que entre las demas obras de piedad, que exercita es su principal instituto) en que con tanta gloria de Dios y edificacion de los Fieles se ha ocupado con continuo desvelo è infatigable trabajo desde el principio de su fundacion hasta el tiempo presente; Y deseosa su charidad de aprovechar mas en la Viña de la Iglesia y de coger mas colmados frutos para el Señor en aumento de la Religión Catholica, ocurrio à la que es Madre y Maestra de toda Santidad, fuente y origen de todas las gracias que el Señor comunica à sus Fieles en la tierra à la Santa Iglesia Romana, para que como dispensadora de los celestiales thesoros le comunicasse las gracias e indul[f. 3r]gencias que se juzgasse convenir a la mayor honra y gloria de Dios, y bien de las almas: donde con divina providencia, atendido el instituto de esta Sagrada Vnion y Confraternidad, fue vnida y agregada à la dicha Archicofradia de la Doctrina Christiana, fundada en la Basilica de Nuestro Padre San Pedro, por el eminentissimo Señor Gaspar Carpineo, Presbytero Cardenal del titulo de San Silvestre, Vicario General de Nuestro Santísimo Padre Inocencio Vndecimo, y los demas Oficiales que representan la dicha Archi-Cofradia, y le concedieron y comunicaron todas las gracias, indulgencias y privilegios, que à dicha Archi-Cofradia, y à las demas Cofradias à ella agregadas, les fueron concedidas por Nuestro Muy Santo Padre Paulo Papa Quinto en la 
Bula referida, cuyo tenor à la letra vino inserto en la de Agregacion, que por el Protector y demas Oficiales de dicha Archi-Cofradia se despacho à favor de nuestra Vnion, su data en Roma a quatro de Henero del año de mil seiscientos y setenta y siete y el primero del Pontificado de Nuestro Santísimo Padre Inocencio Vndecimo, passada por el Apostolico y Real Consejo de la Santa Cruzada, y por el Real de las Indias.

Con que por la Misericordia divina, y la intercession de Nuestro glorioso Padre y Patron San Phelipe Neri, se halla oy nuestra Vnion en aptitud de poder aprovechar mucho à las almas por medio de la enseñança y explicacion de la Doctrina Christiana, y lograr con el continuo desvelo de sus Ministros Operarios colmados frutos de reformacion de costumbres y destierro de la ignorancia de las cosas necessarias para la salvacion, especialmente en la gente pequeña y vulgar de esta Ciudad, que es vno de los principales fines con que se fundò nuestra Vnion: esperando en la divina providencia se ha de verificar de ella la

[Al margen] Matthei cap. 13

Parabola de la Mostaza que nos enseñò Christo en el Evangelio; pues aviendo sido tan pequeña en su principio, que començò por treinta y tres sacerdotes el año de mil seiscientos y cinquenta y ocho, la ha ensalçado tanto la Magestad divina que pueda recebir à su sombra y acoger en [f. $3 \mathrm{v}]$ el dilatado seno de su charidad ardiente à todos los que desseosos de su salvacion quisieren aprovecharse del pasto saludable de la Doctrina Christiana y del thesoro inestimable de indulgencias que a sus congregantes y cofrades se comunica. De que debemos dar muchas gracias al Señor por beneficio tan singular, y mostrarnos muy reconocidos

[Al margen] Vrbano 8. in Bulla Canonizationis Sanctus Philippi Nerii §. 29. et 30. tomus 4. Bullarium Cherubini Constitución $2^{\text {a }}$ Rationi congruit.

à Nuestro Santo Patron, que lo que no pudo conseguir en su persona, porque assi convino, que fue passar à las Indias à propagar la Fe y Predicacion evangelica, aunque lo desseò y procurò con el fervoroso zelo que ardia en su pecho de la salud de las Almas, ha alcançado de Dios que sus hijos y Congregantes suplan algo de lo mucho que desseò y por si no pudo cumplir ni executar.

Y porque para el feliz govierno de nuestra Vnion de San Phelipe Neri y Cofradia de la Doctrina Christiana, y en orden à conseguir el fin de tan santo, vtil, y loable instituto como el que professamos, se nos da facultad 
por la dicha Bula para hazer qualesquiera estatutos, Reglas y Constituciones, como no sean contrarios al Derecho [ilegible] Santo Concilio de Trento, y Bulas Apostolicas; y de m[ilegible]darlas tantas quantas vezes fuere necessario, en todo ò en parte, segun las ocurrencias y calidad de los tie[ilegible]pos, y en lugar de ellas hazer y publicar otras de nuevo: [ilegible] sando de la dicha facultad Nos el Prefecto y Oficiales [ilegible] la Vnion de Nuestro Padre San Phelipe Neri que à la sazon era [ilegible] en la Junta que tuvieron en cinco de Diziembre de mil seiscientos y [ilegible]tenta y ocho años consi[ilegible] eron y formaron las que parecieron conve[ilegible] entes, que por no averse aprobado por varios accidente[ilegible] parecio necessario bolver à ver su borrador en la Junta de oy dia de la fecha de estas, donde concurrimos e[ilegible] Licenciado Santiago de Zuricalday Prefecto, el Licenciado Martin de [ilegible]llana, el Licenciado Diego Calderon Benavides, el Doctor Don Juan Millan de Poblete, Cura de la Santa Iglesia Cathedral, el D[ilegible] Joseph Vallejo de Hermosillo, Consultores; el Licenciado Juan de O[ilegible]bares Torralbo, thesorero; y el Doctor Alonso Alberto de Vela[ilegible] Cura de dicha Santa Iglesia y Procurador de la Doctrina a[ilegible][f. 4r]te el Licenciado Phelipe Neri Martinez, Secretario. Y en dicha Junta determinamos hazer è hizimos las Reglas y Constituciones, que segun el tiempo presente nos han parecido necessarias y convenientes para la direccion y govierno de la dicha Cofradia de la Doctrina Christiana: sujetandolas en todo à la correccion y censura del Ilustrísimo Señor Doctor Don Francisco de Aguiar y Ceijas, Arçobispo de esta Metropoli, nuestro dignissimo Prelado, y especial Protector de Nuestra Vnion. Y son en la forma siguiente.

Capitulo $1^{\circ}$ Del Gobierno de la Cofradia de la Doctrina Christiana.

[Al margen] $1^{\mathrm{a}}$

El primer cimiento y basa fundamental de esta Piadosa y devota Cofradia de la Doctrina Christiana es la Santissima Cruz, en que Christo, Salud y Vida nuestra padecio y murio por salvarnos; y debaxo del estandarte de esta soberana divisa, que es la insignia y señal del Christiano, han de militar todos los congregantes de nuestra Vnion de San Phelipe Neri, los Ministros operarios y Cofrades de la Cofradia de la Doctrina Christiana, eligiendola, como desde luego la elegimos por principal Patrona y tutelar de ella, para que por medio de su proteccion, y la de la Sacratissima Virgen Maria, Nuestra Señora de las 
Nieves, y de Nuestro Glorioso Padre San Phelipe Neri, Patrones de Nuestra Vnion y Oratorio, cuyo auxilio imploramos, sea Nuestro Señor servido de conservarla, aumentarla, y defenderla de todos sus enemigos visibles è invisibles.

[Al margen $] 2^{\mathrm{a}}$

Item suplica humilmente ${ }^{24}$ Nuestra Vnion à su Señoria Ilustrísima el Señor Arçobispo de esta Ciudad y Arçobispado de Mexico, como à Nuestro Pastor y especial Protector de ella, y de esta santa Cofradia de la Doctrina Christiana; y al Muy Ilustre y Venerable Señor Dean y Cabildo de esta Santa Iglesia en Sede Vacante, se sirva con su Charidad Paternal y zelo Pastoral de ampararla, patrocinarla, ampliarla y dilatarla para la mayor honra y gloria de Dios, y bien de [f. 4v] las almas y recebir debaxo de su Proteccion à todos sus Congregantes y Ministros Operarios para que con el fomento de tan Suprema Authoridad se fervorizen todos, dedicandose al empleo de tan santo exercicio, y de tanto agrado del Señor.

[Al margen $] 3^{\mathrm{a}}$

Item se ordena que la Vnion de San Phelipe Neri ha de quedar, como queda, en el estado que hasta el tiempo presente ha tenido y tiene en quanto al numero de ciento y veinte Sacerdotes de que se compone, y las obligaciones de Missas, Platicas, Sermones, Visitas de hospitales, y demas exercizios y modo de govierno que tiene; sin que se entienda alterar ni mudar cosa alguna de las que segun ellas observa y acostumbra, por muchas y eficaces razones que movieron à establecer el dicho numero; y que de ampliarlo resultarian muchos inconvenientes, y no se podría cumplir exactamente con las obligaciones referidas, y especialmente con las de las Missas.

[Al margen] $4^{\mathrm{a}}$

Item se ordena que el govierno y direccion de todo lo concerniente a la Cofradía de la Doctrina Christiana ha de estar à cargo de los Padres Prefecto y Oficiales de la Vnion de nuestro Padre San Phelipe Neri según y en la forma que està todo lo tocante à dicha Vnion.

${ }^{24}$ Adverbio en desuso de humildemente. Véase "humilmente", Real Academia Española, en https://dle.rae.es/humilmente, consultado el 17 de mayo de 2020. 
[Al margen] $5^{\mathrm{a}}$

Y los dichos Padres Prefecto y Oficiales, y demas Congregantes, que al presente son y adelante fueren, han de procurar mostrar con las obras, que son hijos y herederos del Espiritu de Nuestro Santo Padre y Patron San Phelipe Neri en el zelo y fervor con que han de promover vna obra tan santa, y cooperar à vn ministerio tan del servicio de Dios y bien de las almas.

[Al margen] $6^{\mathrm{a}}$

Y porque la experiencia ha mostrado ser necessario que aya vn Procurador de la Doctrina Christiana a cuyo cargo estè el procurar y solicitar con toda vigilancia y cuydado la conservacion y aumento de todo lo tocante à este ministerio, assi en lo espiritual como en lo temporal por cuya razon se nombrò para él al Doctor Alonso Alberto de Velasco, Cura de esta Santa Iglesia Cathedral, Abogado [f. 5r] y Consultor del Santo Oficio de la Inquisicion de esta Nueva España, en la eleccion que se hizo de Oficiales de esta Vnion en diez y siete días del mes de Mayo del año pasado de mil seiscientos y ochenta: Y en essa conformidad se ordena que cada tres años se haga eleccion de Procurador de la Doctrina Christiana juntamente con los demas Oficiales de la Vnion; el qual podra ser reelecto todas las vezes que el Padre Prefecto y Oficiales de la Junta juzgasen ser conveniente y vtil segun lo que se huviere experimentado.

\section{[Al margen] $7^{\mathrm{a}}$}

Y aunque el numero de los Congregantes de la Vnion no ha de poder exceder del de ciento y veinte por las razones y motivos expressados en la tercera Regla de este capitulo: toda via se han de poder recebir, y recebiran por Ministros Operarios y Cofrades de la Doctrina Christiana todos los Sacerdotes, assi Seculares, como Regulares, que lo pidieren: Los quales guardaran las Reglas y Constituciones de esta Cofradia, sin quedar obligados en manera alguna à guardar las que precisamente tocan à la Vnion, ni la Vnion para con ellos ha de quedar obligada à las Missas, ni lo demas que observa con sus Congregantes vivos y difuntos. Y para que tengan noticia de las obligaciones que les tocan, el dia que fueren recebidos por Ministros Operarios se le darà à cada vno demas del Sumario comun de las indulgencias, otro particular de las Reglas que han de guardar los Ministros Operarios de esta Santa Cofradía. 
[Al margen] $8^{\mathrm{a}}$

Y para que se consiga el fin que se dessea y todos logren el inestimable thesoro de las muchas indulgencias con que la divina Magestad ha querido favorecer à esta Ciudad por medio de esta Santa Cofradía, et nemo se abscondat à calore eius ${ }^{25}$ se recebiran por cofrades y hermanos de la Cofradia de la Doctrina Christiana (no de la Vnion) à todas y qualesquier personas de ambos sexos, de qualquier edad, estado, calidad, y condicion que sean, como se ha practicado desde que se publicò la Bula de Agregacion [f. 5v], y se les advertira antes de ser recebidos que para el dia que fueren escritos y assentados en el Libro de la dicha Cofradia y recebidos en ella, se dispongan con vna buena Confession de todos sus pecados, y los que fueren capaces reciban el Santissimo Sacramento de la Eucharistia para que consig[ilegible] la indulgencia plenaria que està concedida à los Cofrades en el dia de su entrada.

[Al margen] $9^{\mathrm{a}}$

Y avrà vn Libro, ò Libros, en que se assentaràn los Ministros Operarios, y demas Cofrades con separacion que estarà à cargo de la persona ò personas que se eligiere y n[ilegible]brare por los Padres Prefecto y Oficiales de nuestra Vnion: las quales tendran cuydado de assentar los Ministros operarios y demas Cofrades, como se ha dicho en las Reglas antecedentes, sin que se les pida ni lleve cosa alguna por via de limosna por el assiento, sino tan solamente vn real para el costo del Sumario de las indulgencias y catecismo porque con esso aya mas facilidad de que se assienten por Cofrades todo genero de personas.

\section{[Al margen] $10^{\mathrm{a}}$}

Y se le darà à cada vno de los Cofrades el Sumario de las indulgencias y Reglas comunes que han de guardar, ò por lo menos vno para cada familia, para que tengan noticia de las indulgencias que se ganan, y de las diligencias que deben hazer para conseguirlas.

25 "Y nadie que pueda esconderse de su calor". Paráfrasis del salmo 18, versículo 7, en Clementine Vulgat, Project, en http://vulsearch.sourceforge.net/html/Ps.html, consultado el 18 de mayo de 2020 . 
[Al margen] $11^{\mathrm{a}}$

Y vsando de la facultad que por la Bula de Agregacion se concede à Nuestra Vnion de poder elegir y señalar vna Fiesta principal y titular en cuyo dia ganen indulgencia plenaria todos los Cofrades de la Cofradia de la Doctrina Christiana, que verdaderamente arrepentidos y confessados recibieren el Santissimo Sacramento de la Eucharistia al tiempo que se presentò la dicha Bula de Agregacion se eligio y senalo ${ }^{26}$ por Fiesta principal y titular de la Cofradia de la Doctrina Christiana la de la Invencion de la Santísima Cruz, que es a tres de Mayo, para que los Cofrades que confessaren y comulgaren en esse dia ganen la indulgencia plenaria referida.

[Al margen] $12^{\mathrm{a}}$

Y nuestra Vnion celebrarà en su Oratorio, como hasta [f. 6r] aqui lo ha hecho, la Fiesta de la Invencion de la Santissima Cruz cada año en su dia tres de Mayo con Missa y Sermon y la solemnidad mas decente que pudiere, y assistiran à ella con sobrepellices los Congregantes de nuestra Vnion, y Ministros Operarios de la Doctrina Christiana, que no tuvieren legitimo impedimento. Y à la tarde de dicho dia à las quatro saldra de nuestro Oratorio vna devota Procession de nuestros Congregantes y hermanos Cofrades, que iràn rezando la Doctrina hasta la Santa Iglesia Cathedral, donde se darà fin con vna Platica breve y explicación de la misma Doctrina Christiana: $\mathrm{y}$ se procurarà que en vn acto tan piadoso y de tanto exemplo como este se haga con toda devocion, modestia y edificacion.

[Al margen] $13^{\mathrm{a}}$

Y por quanto Su Santidad concede por otra clausula de dicha Bula à todos y à cada vno de los Fieles Christianos de ambos sexos de qualquier edad que sean, acostumbrados à assistir en las escuelas de la Doctrina Christiana para aprenderla, que en qualquier dia de la Beatissima Virgen Maria, ò en otra Fiesta que se señalare por los Superiores de dicha Cofradia, confessaren sus pecados, tres años de indulgencia, y à los que fueren habiles para comulgar y recibieren devotamente el Santísimo Sacramento de la Eucharistia, cinco años: Vsando de la dicha facultad se eligio asi mismo y se señalò al tiempo que se presentò la Bula de Agregacion, el dia de la Espectacion del Parto felicissimo de Nuestra Señora, que es à diez y ocho de Diziembre, para que los

${ }^{26}$ El original no presenta virgulilla. Se puede leer: "señaló". 
que hizieren las diligencias que la dicha Bula pide, ganen esse dia las indulgencias referidas. Y la eleccion y assignacion de dichas dos Fiestas de la Invencion de la Santísima Cruz, y de la Expectacion de Nuestra Señora se aprobò y confirmò por el Ilustrísimo y Excelentísimo Señor Maestro Don Fray Payo de Ribera, Arçobispo que fue de esta Santa Iglesia de Mexico, y Virrey de esta Nueva España, en su auto en que mandò publicar dichas indulgencias: Y desde entonces se han executado estas Constituciones, diez, once, doce y treçe ordenamos se guarden y executen perpetuamente.

\section{[f. 6v]}

Capítulo $2^{\circ}$. Reglas que han de observar los Ministros Operarios y Visitadores de la Doctrina Christiana.

[Al margen $] 1^{\mathrm{a}}$

Para que fuesse mas frequente y dilatada por toda la Ciudad la eseñança de la Doctrina Christiana, y se consiguiesse el fruto que se dessea por el Sagrado Concilio tridentino y Mexicano, Bulas Apostolicas, especialmente la de Agregacion de nuestra Vnion y Confraternidad, que es que todos la sepan y la entiendan, como tienen obligacion, pidio y rogò de nuevo ruega y pide nuestra Vnion à los Señores Prebendados de esta Santa Iglesia, à los Curas del Sagrario de ella y de las demas Parroquias de esta Ciudad, y a los demas sacerdotes que se hallaren con idoneidad, y Dios les diere espiritu para ello se dignen de entrar por Ministros operarios de esta Cofradia, porque la Miès es mucha, y los operarios pocos: $\mathrm{Y}$ assi hemos menester rogar al Señor embie à su Miès los operarios que vè son necessarios, y por [ilegible] medio espera de su divina Piedad nuestra Vnion los ha de conseguir.

\section{[Al margen $] 2^{\mathrm{a}}$}

[Al margen] Concilium Mediolanum $3^{\circ}$, titulo de Scholis Doctrinae Christianae. Et Mediolanum $4^{\circ}$ parte $1^{\mathrm{a}}$ titulo de Doctrina Christiana Mexicano, titulo de Doctrina Christiana $\S 1^{\circ}$

Y con efecto, de permisso y licencia del Ilustrísimo y Excelentísimo Señor Maestro Don Fray Payo de Ribera, Arçobispo que fue de este Arçobispado y Protector de la Vnion, se dio principio à la explicacion y enseñança de la Doctrina Christiana, luego que se publicò dicha Bula de Agregacion, en las siete escuelas que se fundaron en la manera siguiente. 
[Al margen] $3^{\mathrm{a}}$

La primera en la Santa Iglesia Cathedral de esta Ciudad à quien se debe la Primacia, como à la Matriz y Cabeça de las demás: donde (avido primero el beneplacito de [ilegible] Señores Dean y Cabildo, y el consentimiento de los Curas del Sagrario de ella, à quienes incumbe este ministerio)

[Al margen] Concilio Tridentino, sessionem 24. capítulo 4. Mexicano vbi supra $§ 3^{\circ}$

se ha explicàdo y explica la Doctrina Christiana todos los Domingos por la mañana despues de la Missa mayor en los dias que no ay sermon, porque en nada se embaraçe à los Oficios divinos, de diez y media à once [f. 7r] poco mas ò menos: y se eligio esta hora, y no por la tarde por ser la del concurso del pueblo à oir Missa, y la mas dese[ilegible]baraçada de Horas Canonicas. Donde se ha experimentado el piadoso zelo de los señores Prebendados y Curas de dicha Santa Iglesia, y de los demas Congregantes de nuestra Vnion, que con todo fervor, diligencia, y charidad fraternal se han dedicado y exercitado en este ministerio, aprovechando mucho à los Fieles con el buen olor de su Doctrina, y exemplo, y se espera lo continuaràn infatigablemente.

[Al margen] $4^{\mathrm{a}}$

La segunda escuela se fundò en nuestro Oratorio de San Phelipe Neri, como cabeça donde està fundada esta Cofradia, raiz y origen de las demas escuelas de ella. La tercera y quarta en las Parroquias de Santa Cathalina Martyr y la Santa Veracruz obtenido primero el consentimiento de los

[Al margen] Concilium Mediolanum 4 parte $1^{\mathrm{a}}$ titulo de Doctrina Christiana

curas de ellas. La quinta en la iglesia de la Santísima Trinidad, avido asimismo el consentimiento del Señor Abad de la Congregacion Eclesiastica de Nuestro Padre San Pedro. La sexta en la iglesia del Hospital de la Concepcion de Nuestra Señora que llaman de Jesus Nazareno, con consentimiento de los Capellanes de el. La septima, en los Portales de la plaça mayor de esta Ciudad, donde parece mas precisa y necessaria la enseñança de la Doctrina Christiana por la mucha gente vulgar que ay en ella, y la mas necessitada de este socorro espiritual. Y en dichas seis escuelas se continuarà la explicacion y enseñança de la Doctrina Christiana como hasta aquí se ha hecho todos los domingos por la tarde, en que no huviere legitimo 
impedimento, salvo si en alguna de ellas se reconociere ser mas vtil y conveniente que se haga por la mañana por el mayor concurso del auditorio.

[Al margen $] 5^{\mathrm{a}}$

Y si se reconociere necessidad y vtilidad de fundar y aumentar otras y la copia de Ministros diere lugar à ello, nuestro Padre Prefecto, Consultores, y Procurador de la Doctrina Christiana tendran cuydado de que este Pasto espiritual tan importante à la salud de las almas se comunique à todos en quanto fuere possible, asignando opera[f. $7 \mathrm{v}]$ rios idoneos à las partes donde conviniere.

\section{[Al margen] $6^{\mathrm{a}}$}

Y para la perpetuidad y permanencia de dichas escuelas se nombran y eligen desde ahora para siempre p[ilegible] Ministros Operarios para la Santa Iglesia Cathedral, Parroquias de Santa Cathalina Martyr y la Santa Veracruz, à los Curas de ellas como Congregantes de nuestra Vnion, demas de la obligacion que principalmente les toca, como tan propria de su ministerio, por Derecho y Santo Concilio de Trento.

\section{[Al margen] Concilium Mediolanum 4 parte $1^{\mathrm{a}}$ titulo de Doctrina Christiana $\S$ vltimo}

Y los demas Congregantes y Operarios de nuestra Vnion les ayudaràn las vezes que pudieren, y les fuere pedido por dichos Curas, portandose en esto con la charidad de hermanos è hijos del espíritu de Nuestro Padre San Phelipe Neri. Para nuestro Oratorio, y demas escuelas se eligiran los Ministros Operarios en quienes concurrieren la idoneidad y parte[ilegible] necessarias para vn ministerio tan importante.

$[\mathrm{Al}$ margen $] 7^{\mathrm{a}}$

[Al margen] Concilio Mexicano, libro $1^{\circ}$ titulo de Doctrina Christiana rudibus tradenda $\S 1^{\circ}$

Y porque parece mas necessario con los esclavos y gente vulgar el especial cuydado y charitativa solicitud [ilegible] esta Confraternidad en instruirlos en los rudimentos de nuestra Santa Fe Catholica, y que lo que aprendieron quando pequeños, no lo olviden quando grandes, y hagan el [ilegible] precio que deben de cosa que tanto les importa, se tendra con semejante gente, y con los niños, el estilo y orden siguiente. 
[Al margen] $8^{\mathrm{a}}$

[Al margen] Concilio Millanese 1 sub Santo Carolo parte $1^{\mathrm{a}}$, titulo de Fidei initiis à Parochi tradenda. Concilio Millanese $5.1^{\mathrm{a}}$ parte, titulo $2^{\circ}$ quae ad praedicatione verbi Dei [ilegible]. Concilio Mexicano titulo $1^{\circ}$ de Doctrina Christiana $\S 2^{\circ}$

Cada vno de los Padres Ministros Operarios de la Doctrina Christiana que fuere señalado los Domingos por la tarde à la hora competente juntarà à sonido de campana, as[ilegible] en nuestro Oratorio, como en cada vna de dichas iglesias, ò escuelas, respectivè, à los niños, esclavos, criados, y demas gente vulgar: Y en voz alta hecha primero la señal de la Cruz y alabado el Santísimo Sacramento, si fuere dia de Estacion en Roma, les anunciarà las particulares indulgencias que aquel dia ganan los Cofrades que asisten a oir y aprender la Doctrina Christiana y los exortarà à que se dispongan à ganarlas haziendo de todo corazon vn Acto de Contricion, diziendoselo en la forma acostumbrada, assi para que se pongan en Gracia de Dios para ganar las indulgencias [f. 8r] como para que sabiendolo bien, se habituen à hazerlo con frequencia. Despues rezarà en voz alta con ellos las oraciones segun se contienen en el Cathecismo, repartiendolas en dos ò tres dias, porque lo dilatado de ellas no sea molesto al auditorio, y se les haga mas breve y suave este exercizio, procurando disponerlo de manera que lleguen à saberlas todas. Luego se les enseñaràn dos ò tres Preguntas del Cathecismo con sus Respuestas (por el que ha sacado à la luz nuestra Vnion, que es breve y contiene los Mysterios mas principales de la Fe, y que estan todos obligados à saber) haziendo que ya vno, ya otro de los oyentes repita la Respuesta y con la Pregunta la procuren llevar de memoria, dandoselas à entender con el estilo mas claro y mas llano que se pudiere, acomodandose con la capacidad, modos de hablar, y entender de los oyentes. Y de los mismos articulos ò puntos que les huviere explicado, ò enseñado, hará el Ministro Operario con el auditorio actos de las tres virtudes theologales, Fe, Esperança, y Charidad, de suerte, que vayan los oyentes respondiendo al acto de Fe, que assi lo creen; al de la Esperança, que assi lo esperan; al de la Charidad que assi dessean y quieren amar y aman à Dios nuestro Señor. Y asimismo quando el punto ò puntos fueren de los Mandamientos, los exercitarà en hazer buenos propositos en la observancia y guarda de los Mandamientos, respondiendo à cada vno, que dessean y proponen cumplirlo muy por entero con la gracia de Dios. Y en esta forma, $\mathrm{v}$ otra semejante, se haràn dichos actos y propósitos: 
[Al margen] Padre Lucena en la Vida de San Francisco Xavier, libro $2^{\circ}$ capítulo $3^{\circ}$

en los quales exercitaba San Francisco Xavier à sus oyentes, quando les enseñaba la Doctrina Christiana. Y finalmente seràn exortados con charidad Paternal à la continuacion de tan necessario y provechoso exercizio: $\mathrm{Y}$ aviendo rezado vn Padre Nuestro, y vna Ave Maria por la intencion de esta Santa Cofradia, y alabando al Señor, serán embiados en paz. Y los Ministros de Lengua Mexicana haràn lo mismo con los Naturales que no hablan la Castellana, vsando para ello de la Cartilla, ò Cathe[f. 8v]cismo Mexicano.

[Al margen $9^{\mathrm{a}}$

[Al margen] Concilio Millanese $51^{\text {a }}$ parte, titulo $2^{\circ}$ quae ad praedicatione Verbi Dei etcétera. Concilio Mexicano, libro $1^{\circ}$ titulo $1^{\circ}$ de Doctrina Christiana $\S 3^{\circ}$

Y quando el auditorio fuere de personas de mayor capacidad, y que no necessitan de la enseñança de los Rudimentos de la Fe, se les harà vna Platica, que no passe de media hora, en que se explicaràn vno v dos articulos ò puntos de la Doctrina Christiana con estilo claro

[Al margen] Concilio Mexicano libro $1^{\circ}$ titulo $1^{\circ}$ de Praedicatione verbi Dei $\S 5^{\circ}$

dexando questiones invtiles, controversas y dificultosas que son mas para Cathedras que para Pulpito, ajustandose à la Doctrina del Cathecismo Romano, v otro de los aprobados, y se referira vn exemplo en comprobacion de lo que se huviere explicado; y en ninguna ocasion se omitira el acto de contricion, para que los oyentes se dispongan à ganar las indulgencias; ni los actos de las tres Virtudes Theologales, y buenos propositos, como se dixo en la Regla antecedente, para que se logre el inestimable fruto que por medio de ellos se consigue. Y se advierte que solo

[Al margen] Concilio Tridentino sessiones $5^{\mathrm{a}}$ capítulo $2^{\circ}$ et sessiones 24 capítulo $4^{\circ}$ Concilio Mexicano libro $1^{\circ}$ titulo $1^{\circ}$ de Praedicatione verbi Dei $\S 2^{\circ}$ Et de Doctrina Christiana $\S 1^{\circ}$ $2^{\circ} 3^{\circ}$ et $4^{\circ}$

los Curas, à quienes toca por su oficio, y los demas Presbyteros, que tienen licencia de predicar, han de poder hazer las dichas Platicas, y explicacion de la Doctrina Christiana; y los que no la tuvieren, enseñaràn las Oraciones y el Cathecismo à la gente que lo necessitare en la forma que se refiere en la Regla antecedente segun lo dispuesto por los Sagrados Concilios, Tridentino y Mexicano. 
[Al margen] $10^{\mathrm{a}}$

[Al margen] Concilio Mexicano titulo $1^{\circ}$ de Doctrina Christiana $\S 6^{\circ}$

Assimismo se ordena que el Padre Prefecto, ò el Procurador de la Doctrina Christiana, cuyden, siempre que se pueda, embiar à las carceles, y obrages Ministros Operarios, que los Domingos, ò días Festivos, les enseñen y expliquen la Doctrina Christiana, para que los pobres que en ellos moran, no carezcan, por encerrados, de este Pasto espiritual.

[Al margen $] 11^{\mathrm{a}}$

[Al margen] Concilio Millanese $5^{\circ}$ Sub Santo Carolo titulo $2^{\circ}$ quae ad praedicatione verbi Dei et Doctrina Christiana pertinent. Concilio Mexicano libro $1^{\circ}$ titulo $1^{\circ}$ de Sacramentis Doctrina Christiana ignaris non administrandis $\S 1^{\circ}$ in fine

A los Padres Confessores se ruega y encarga muc[ilegible] se muestren severos y graves con los penitentes que no Supiere la Doctrina Christiana, ò, à lo menos, lo que [ilegible] ella estan obligados à aprender y saber debaxo de pecado mortal, vsando para ello de todos los medios co[ilegible] [f. 9r] venientes que su prudencia les dictare, y están dispuestos por los Concilios, y aconsejan los authores.

[Al margen] $12^{\mathrm{a}}$

[Al margen] Concilio Mexicano libro $1^{\circ}$ titulo $1^{\circ}$ de Praedicatione verbi Dei $\S 4^{\circ}$

Assimismo se pide y ruega à todos los padres predicadores que en sus sermones, demas de la reformacion de costumbres, que es la principal obligacion de su ministerio, procuren tocar y exponer, segun el assumpto ò materia ocurrente, algun punto de doctrina christiana, para que assi sea mas abundante la cosecha de frutos espirituales, y se logre en todas ocasiones el thesoro de indulgencias de esta santa Cofradia.

[Al margen $] 13^{\mathrm{a}}$

Y porque su Santidad concede siete años y siete quarentenas de perdon de las penitencias impuestas, ò en qualquiera manera debidas a todos los cofrades de dicha Cofradia, verdaderamente arrepentidos, confessados y comulgados en qualquier dia en que se publicare, y assimismo siguiendo 
[Al margen] Concilio Millanese 3 Sub Santo Carolo titulo $2^{\circ}$ de Scholis Doctrina Christiana

lo dispuesto por el Concilio Milanese tercero, se ordena que cada vno de los Ministros Operarios publique cada año en la Dominica de la Septuagessima, y si estuviere impedida, en la de la Sexagessima, las indulgencias de esta Cofradia, leyendose el Sumario de ellas en todas las iglesias ò escuelas de la Doctrina Christiana.

Y leidas se harà vna breve ponderacion de la importancia de ellas y de la doctrina christiana, y de la obligacion que todos tienen de saberla para salvarse, y quanto lo desea y solicita la Santa Sede Apostolica, pues nos ha concedido por medio de esta santa Cofradia vn thesoro tan inestimable, como el de sus indulgencias, para atraer mas suavemente como Madre piadosa à sus fieles hijos con este sagrado interès al perfecto cumplimiento de tan precisa obligacion. Y se exortarà à todos los que no fueren cofrades, à que se assienten, porque no siendo cofrades no ganan las indulgencias. Y en la Dominica, ò fiesta antecedente à la Septuagessima, se harà acuerdo à los Cofrades de esta indulgencia, para que confiessen, y comulguen, y se hallen presentes a la publicacion para ganarla, para que por este medio procuren entrar en gracia de Dios [f. 9v] en el Santo tiempo de la Quaresma.

[Al margen] $14^{\mathrm{a}}$

Assimismo tendran especial cuydado los Comissarios y Ministros Operarios de exortar à sus oyentes Cofrades en la Dominica que precede à la de la Fiesta de la invencion de la Santísima Cruz (que es la titular de nuestra Cofradia) [ilegible] que en esse dia se dispongan con vna buena confession de todos sus pecados, y reciban el Santísimo Sacramento de la Eucharistia, para ganar la Indulgencia plenaria, que concede su Santidad à todos los cofrades que confessaren y comulgaren en el dia de la Fiesta principal y titular de esta Cofradia; y se les advierta, que para ganarla [ilegible] es necessario visitar el Oratorio de Nuestro Padre San Phelipe Neri [ilegible] mas diligencia que confessar y comulgar dicho dia en qualquiera Iglesia; que por ser tan facil y à poca [ilegible] se debe hazer mayor aprecio de esta indulgencia plenaria, y disponerse mejor para ganarla.

[Al margen] 15

Assimismo avisaràn los Ministros Operarios a los Cofrades, que los que pudieren, se hallen la tarde de la Fiesta referida de la Invencion de la Santísima Cruz à la Procession de la Doctrina, que saldrà de nuestro Oratorio 
à las quatro, hasta la Santa Iglesia Cathedral, para que ganen los docientos dias de indulgencia que su Santidad concede por dicha Bula à los Cofrades que se hallaren à [ilegible] Processiones que por mandado del Ordinario se hizieren debaxo del Estandarte de dicha Cofradia.

[Al margen] $16^{\mathrm{a}}$

Assimismo tendran cuydado los Ministros Operarios de hazer recuerdo à todos los Fieles Christianos de los [ilegible] años de indulgencia que ganan los que confiessan, y cinco si comulgan, el dia de la Expectacion del Parto de Nuestra Señora, segun queda dicho en la Regla vltima del Capitulo primero. Y lo mismo haràn de las demas indulgencias contenidas en la Bula, acordandolas à sus tiempos, y con las circunstancias que en ella se refieren, para que no pierdan ocasión alguna los Cofrades para el mayor aprovechamiento de sus almas y logro del thesoro de tantas indulgencias, como su San[f. 10r]tidad les concede.

[Al margen] $17^{\mathrm{a}}$

Y porque segun la Bula de Nuestro Muy Santo Papa Paulo Quinto es preciso se nombren Visitadores que visiten las Escuelas de la Doctrina Christiana; desde ahora para siempre se nombran por Visitadores à los Padres Prefecto y Consultores de la Vnion de Nuestro Padre San Phelipe Neri que son al presente y adelante fueren. Y si parecieren necessarios mas Visitadores segun el numero de las Escuelas que se fundaren, eligiràn de los sacerdotes de la Vnion aquellos en quienes hallaren concurrir el zelo, y prudencia, y las demas partes necessarias para dicho Ministerio; y à cada vno se le assignaran las Iglesias ò Escuelas que ha de tener à su cargo para visitarlas, y guardaràn el orden siguiente.

[Al margen] $18^{\mathrm{a}}$

[Al margen] Concilio Millanese 3 parte $1^{\mathrm{a}}$ titulo $2^{\circ}$ de Scholis Doctrina Christiana, versiculo Scholas

Los Padres Visitadores tendran cuydado de visitar las Iglesias ò Escuelas de la Doctrina Christiana que se les encomendaren, y se informaràn, assi de la puntualidad y zelo de los Ministros Operarios y estilo que se observa como de la frequencia del pueblo, y progressos espirituales de esta Santa Cofradia, y procuraràn la observancia de las Reglas, haziendo que esta obra camine 
felizmente: y de todo ello, y lo demas que conviniere, haràn relacion los lunes primeros de cada mes en la Junta de Prefecto y Oficiales que se tendrà en nuestro Oratorio: y si en ella pareciere necessario advertir v ordenar algo à los Eomissarios y demas Ministros Operarios, lo haràn con la prudencia y modestia que conviene, para la permanencia, aumento y conservacion de esta Santa Cofradia.

\section{[Al margen] 19a}

[Al margen] Concilio Millanese 4 parte $1^{\mathrm{a}}$ titulo 26 de Doctrina Christiana in fin

Los demas Padres Congregantes ayudaràn à los Padres Operarios en las Iglesias de su cargo, enseñando y explicando la Doctrina Christiana en ellas, y en las carceles y obrages de esta Ciudad al tiempo y quando se lo pidieren y encargaren, guardando en todo lo dispuesto por estas Reglas y Constituciones, y los avisos que se les dieren por los Padres Visitadores de lo que conviniere.

[Al margen] $20^{\mathrm{a}}$

Y finalmente todos los Padres Congregantes, [f. 10v] Visitadores, y Ministros Operarios de la Doctrina Christiana, tendran siempre presentes à los ojos de la consideracion las muchas obligaciones de que se encargaron por el Sacerdocio y demas ministerios en que Dios los ha puesto, de Padres, Pastores, y Medicos espirituales de las almas, de que todos hemos de dar rigorosa quenta, et sanguis earum [ilegible] manibus nostris requiretur. $\mathrm{Y}$ assi procuraran con todo esfuerço anteponer el provecho y vtilidad que se sigue de cumplirlas, al trabajo y dificultad de la obra, considerando el daño de la omission, el premio que Dios tiene prometido à los buenos operarios, y la pena de los negligentes: acordandose de lo que entre otras cosas dixo Nuestro

[Al margen] Clemens Papae epistola $1^{\mathrm{a}}$ Iacobus frater Domus et refertur tomo $1^{\circ}$ Concili[ilegible]

Padre San Pedro à San Clemente Papa, encargandole el Sumo Pontificado, y cuydado de las almas, y en el a todos los Prelados y Sacerdotes: Propter quos vos, ò Presbyteri, Ecclesiam extollite, et ordinate Sponsam Christi ad pudicitiam. Sponsam autem dico omnem Ecclesiae Congregationem, quae si pudica inventa fuerit à Sponso suo ingentibus ab eo donis et muneribus honorabitur; et vos velut ministrio sponsae, et amici sponsi, ingenti gaudio et laetitia perfruemini. Si verò Sponsa haec reperta fuerit commaculata peccatis, ipsa 
quidem tanquam indigna non tradetur regalibus toris. Vos autem poenas dabitis, si fortè per vestram negligentia vel desidiam obrepserit contagio saerva peccati, etcétera.

Capítulo $3^{\circ}$ De las Reglas comunes de los Cofrades de la Doctrina Christiana [Al margen] $1^{\mathrm{a}}$

[Al margen] Concilio Mexicano libro $1^{\circ}$ de Sacramentis Doctrina Christiana ignaris non administrandis $\S 1^{\circ}$

Los Cofrades de la Doctrina Christiana han de poner todo cuydado y diligencia en saber los Rudimentos de nuestra Santa Fe Catholica, que son el Credo, y Mandamientos, Oraciones y Sacramentos, y las proprias obligaciones de su estado con la mayor perfeccion que pudieren, y su capacidad alcançe. Y para ello acudiran con toda puntualidad à oir y aprender la Doctrina Christiana [f. 11r] los Domingos y demas Fiestas de guardar, à alguna de las Iglesias donde se enseña y explica, pues no les importa menos que el saber lo que deben creer, y los Mandamientos de Dios, y de la Iglesia, que deben guardar para salvarse; que es el negocio de mayor importancia que tenemos.

[Al margen $] 2^{\mathrm{a}}$

[Al margen] Concilio Mexicano, libro $1^{\circ}$, titulo $1^{\circ}$, De Doctrina Christiana, $\S 3^{\circ}$. Concilio Millanese 5 , parte $1^{\mathrm{a}}$, titulo $2^{\circ}$, quae ad praedicatione verbi Dei, et Doctrina Christiana, etcétera., $\S^{\circ}$, Porro Confessarii

Todos los Padres y Madres de familias tienen obligacion de enseñar à sus hijos, criados y esclavos la Doctrina Christiana en sus casas, y si en esto fueren notablemente omissos pecaràn mortalmente: $\mathrm{y}$ assi se les encarga procuren cumplir con tan precisa obligacion, y que los lleven ò embien à las Iglesias, y los enseñen à estar en ellas con el respecto, silencio, y reverencia que se debe; y que oigan y aprendan la Doctrina Christiana donde se enseñare, para que assi se crien con la diciplina y enseñança que conviene, y desde sus primeros años se vayan aficionando à las cosas de la virtud, y exercizios espirituales, y huygan de todo aquello que los puede llevar à la perdicion. 
[Al margen] $3^{\mathrm{a}}$

[Al margen] Concilio Mexicano, libro $1^{\circ}$, titulo $1^{\circ}$, De Doctrina Christiana, $\S 4^{\circ}$. Millanese $1^{\circ}$, titulo de Ludi Magister et titulo de Fidei initiis à Parochi tradenda

Los Maestros de las Escuelas de los niños pondran todo cuydado en que cada dia se diga en ellas la Doctrina Christiana, y aprendan el Cathecismo; y los llevaràn ò embiaràn los Domingos y dias festivos à que oigan la Doctrina Christiana y su explicacion en alguna de las Iglesias donde se enseña: y no permitiran que lean en libros profanos de que puedan aprender cosas malas, ò tomar mal exemplo; sino en libros espirituales y devotos, de donde puedan sacar fruto para la buena criança y educación, obediencia y respecto que deben tener à sus padres y mayores.

[Al margen $] 4^{\mathrm{a}}$

Todos los cofrades encomendaràn à Dios las necessidades de la Iglesia y Prelados de ella; la Paz y Concordia entre los Principes Christianos; la Conversion de los infieles, Hereges, y pecadores, y la conservacion y aumento de esta Santa Cofradia y sus Ministros Opera[f. 11v]rios, y tendran entre si especial comunicacion de las buenas obras como si cada vno las hiziera todas; y por esta intencion rezaran cada dia vn Padre Nuestro y vna Ave Maria.

Las quales Reglas y Constituciones pedimos y suplicamos al Ilustrísimo Señor Doctor Don Francisco de Aguiar y Ceijas, Arçobispo de Mexico, del Consejo de Su Magestad Especial Protector de Nuestra Vnion se sirva de aprobarlas y confirmarlas: y mandar se guarden cumplan y executen. Y sobre todo su Señoria Ilustrísima proveera lo mas conveniente al servicio de Dios nuestro Señor aumento y conservacion de esta Vnion y Confraternidad de la Doctrina Christiana que son fechas en este Oratorio de Nuestro Padre San Phelipe Neri de Mexico, y Sala de sus Juntas en doce dias del mes de febrero de mil y seiscientos y ochenta y tres años, todo Nos Comisarios No vale

Santiago de Çuricalday, Prefecto [rúbrica]

Doctor Joseph Vallejo Hermosillo [rúbrica]

Doctor Alonso Alberto de Velasco [rúbrica]

Bachiller Hernan de Arellano [rúbrica]

Bachiller Diego Calderon Benavides [rúbrica]

Doctor Don Joan Millan de Poblete [rúbrica]

Phelipe Neri Martinez [rúbrica]

[f. 12r-14v, en blanco.] 


\section{FUENTES Y BIBLIOGRAFÍA}

\section{Fuentes inéditas}

Archivo General de la Nación de México, Bienes Nacionales, v. 944, exp. 2, f. 1r-14v. Archivo Histórico Casa Morelos, Diocesano, Gobierno, Visitas, Asientos, c. 57, exp. 14, f. 1r-299v.

\section{Fuentes publicadas}

Gutiérrez, Julián, Memorias Históricas de la Congregación de el Oratorio de la Ciudad de México, y fundada con auctoridad ordinaria, después, con la apostólica, erigida y confirmada en Congregación de el Oratorio, copiada a el exemplar de la que en Roma fundó el esclarecido patriarca san Phelipe Neri, en las quales se da noticia, asi de su fundación como de su apostólica erección y confirmación, y juntamente de muchas de las personas, que en uno y otro tiempo la han ilustrado/recogidas y publicadas por el P. Julián Gutiérrez Dávila, presbytero, preposito, que fue, de dicha Congregación del Oratorio de México, México, Doña María de Ribera, 1736.

Robles, Antonio de, Diario de sucesos notables, 1665-1703. Ed. y pról. de Antonio Castro Leal. T. II. México: Porrúa, 1946.

\section{Bibliografía}

Aguirre Salvador, Rodolfo, Cofradías y asociaciones de fieles en la mira de la Iglesia y de la Corona: arzobispado de México, 1680-1750. México: Universidad Nacional Autónoma de México, 2019.

Aguirre Salvador, Rodolfo. "La reorganización de cofradías del arzobispado de México por Aguiar y Seixas". En Expresiones y estrategias. La Iglesia en el orden social novohispano. México: Universidad Nacional Autónoma de México, Instituto de Investigaciones Históricas, 2017, http://www.historicas.unam.mx/ publicaciones/publicadigital/libros/expresiones/04_09_reorganizacion.pdf, consultado el 4 de junio de 2020.

Ávila Blancas, Luis. Bio-bibliografía de la Congregación del Oratorio de San Felipe Neri de la Ciudad de México siglos XVII-XXI. Querétaro: Imprenta Hidalgo, 2008.

Cano Castillo, Antonio. El clero secular en la diócesis de México (1519-1650). Estudio histórico-prosopográfico a la luz de la legislación regia y tridentina. Zamora, 
Michoacán, México: El Colegio de Michoacán; México: Universidad Pontificia de México, 2017.

Fernández, Martha. "Rastros y efectos. El Museo del Escritor en el ex claustro del Oratorio de San Felipe Neri ‘el Viejo’.” Imágenes. Revista electrónica del Instituto de Investigaciones Estéticas, http://www.esteticas.unam.mx/revista_imagenes/rastros/ras_fernandez12.html, consultado el 9 de junio de 2020.

Marín Cano Arenas, Luis. "La Congregación del Oratorio de México: origen e identidad”. Annales Oratorii, n. 12 (2014): 109-126.

Martínez López-Cano, María del Pilar, y Francisco Javier Cervantes Bello, coords. Expresiones y estrategias. La Iglesia en el orden social novohispano. México: Universidad Nacional Autónoma de México, Instituto de Investigaciones Históricas, 2017, http://www.historicas.unam.mx/publicaciones/publicadigital/libros/ expresiones/04_09_reorganizacion.pdf, consultado el 4 de junio de 2020.

Mazín, Óscar, y Esteban Sánchez de Tagle, coords. Los "Padrones" de confesión y comunión de la parroquia del Sagrario Metropolitano de la Ciudad de México. México: El Colegio de México; Murcia, España: Red Luminaria, 2009.

Núñez Beltrán, Miguel Ángel. La oratoria sagrada de la época del barroco. Doctrina, cultura, actitud ante la vida desde los sermones sevillanos del siglo XVII. Sevilla: Universidad de Sevilla, 2000.

Pastor, Ludovico. Storia dei papi. V. XII. Nel periodo della restaurazione cattolica e della guerra dei Trent'Anni. Leone XI e Paolo V, 1605-1621. Roma: Desclée-Editori Pontifici, 1943.

Pérez Puente, Leticia. Tiempos de crisis, tiempos de consolidación. México: Universidad Nacional Autónoma de México, Centro de Estudios sobre la Universidad; Zamora, Michoacán, México: El Colegio de Michoacán; México: Plaza y Valdés, 2005. Silva Herrera, Rocío. "El perfil pastoral de Francisco de Aguiar y Seijas. Análisis desde su visita pastoral a partir del Libro de visita (4 de diciembre de 1686-9 de abril de 1687).” Tesis de maestría, Universidad Pontificia de México, México, 2010.

Silva Herrera, Rocío. "Francisco de Aguiar y Seijas, pastor del rebaño." Cuadernos de Estudios Gallegos, n. 127 (2014): 123-124, http://estudiosgallegos.revistas. csic.es/index.php/estudiosgallegos/article/view/369, consultado el 18 de junio de 2020.

Vera, Fortino H., comp. Colección de documentos eclesiásticos de México, o sea antigua y moderna legislación de la Iglesia mexicana. T. I. Amecameca: Imprenta del Colegio Católico, 1887, http://cdigital.dgb.uanl.mx/la/1080015731_C/10 80015731_T1/1080015731_042.pdf, consultado el 4 de junio de 2020.

Villagrasa Lasaga, Jesús. "La caridad intelectual de Joseph Ratzinger. Los dos primeros años de magisterio de Benedicto XVI (19 de abril de 2005-7 de julio de 2007)." Ecclesia: Revista de cultura católica, n. 4 (2007): 499-510. 